\title{
ESTUDO DE BIOMASSAS ALTERNATIVAS PARA A GERAÇÃO DE ELETRICIDADE: ANÁLISE DOS ÍNDICES ENERGÉTICOS E EMERGÉTICOS
}

\author{
R. A. ARTIOLI e K. TANNOUS ${ }^{1}$ \\ ${ }^{1}$ Universidade Estadual de Campinas, Faculdade de Engenharia Química \\ E-mail para contato: raartioli@gmail.com; katia@feq.unicamp.br
}

\begin{abstract}
RESUMO - este trabalho tem por objetivo avaliar a eficiência da energia renovável de fontes alternativas de biomassas por meio da análise emergética. As biomassas escolhidas para o estudo são: casca de arroz, fibra de coco, resíduo de eucalipto e bagaço de cana-de-açúcar. As eficiências energéticas relativas foram determinadas a partir da produção disponível desses resíduos no país e com base nos indicadores emergéticos obtidos por meio do mapeamento do ciclo de produção dos potenciais biocombustíveis de interesse. O bagaço de cana-deaçúcar foi a biomassa que apresentou os resultados mais sustentáveis e viáveis para a utilização como fonte alternativa de energia.
\end{abstract}

\section{INTRODUÇÃO}

A dependência atual das fontes de energia fóssil e a preocupação com as consequências para o meio ambiente resultantes do uso desenfreado desse tipo de energia, impulsionaram a busca e o estudo de novas fontes alternativas. De acordo com Carmo (2013), a energia contida nas diversas fontes de biomassa, assim como nos seus diversos produtos e subprodutos derivados (ex.: florestas energéticas, resíduos florestais, agroindustriais e urbanos), pode ser diretamente liberada por meio da combustão ou convertida através de processos termoquímicos e biotecnológicos, gerando uma fonte alternativa com menores emissões de gases poluentes e assim, mais sustentável.

Para verificar os pontos positivos e negativos de cada biomassa, utiliza-se a grandeza emergia, que permite a realização de uma análise estratégica sobre as contribuições envolvidas no processo de produção de um determinado produto, no presente trabalho, as biomassas. A grandeza emergia é expressa em equivalentes de joules de energia solar (seJ) e representa a soma da energia total agregada em um determinado material (Zhang, 2010). Segundo Odum (1996), a análise emergética interpreta o grau de dependência ou não de um sistema quanto à necessidade dos recursos da economia e da natureza, realizando um diagnóstico dos sistemas ou processos que são mais sustentáveis. Esse tipo de análise tem sido muito utilizado para avaliar o desempenho de sistemas agrícolas. Brandt-Williams (2002) realizou a avaliação emergética da agricultura da Flórida/EUA e o conjunto dos resultados mostrou a baixa renovabilidade do modelo de agricultura. Existem diferentes contribuições em um processo de produção, a saber: os recursos renováveis (sol, chuva e vento), os recursos não renováveis (perdas de solo e nutrientes) e recursos econômicos (Materiais e Serviços). 
Segundo Odum (1996), os recursos naturais (I) são classificados em renováveis (R) e não renováveis $(\mathrm{N})$, enquanto os recursos econômicos $(\mathrm{F})$ são classificados em materiais $(\mathrm{M})$ e serviços $(\mathrm{S})$. O somatório das emergias dos recursos utilizados será a emergia total $(\mathrm{Y})$, associado a energia produzida (E). Com a finalidade de mesurar estes recursos de forma global no sistema, o autor definiu vários indicadores emergéticos. Dentre eles estão:

- transformidade (Tr), razão entre a energia acumulada necessária para fabricação de um produto e a energia contida no produto gerado, definida como: $\operatorname{Tr}=\mathrm{Y} / \mathrm{E}$;

- renovabilidade $(\% R)$, que representa o valor porcentual de recursos renováveis utilizados para a produção de um produto ou processo, definida como: \% $\mathrm{R}=100 *(\mathrm{R} / \mathrm{Y})$, quanto maior o valor, maior a renovabilidade do processo e preservação dos recursos naturais em longo prazo;

- razão de rendimento energético (EYR), que indica a contribuição da emergia proveniente do sistema de produção para a economia que consome o produto ou serviço. É um sinalizador da capacidade do sistema produtivo na exploração dos recursos naturais e da economia local, transformando-os em produtos, definido como: $\mathrm{EYR}=\mathrm{Y} / \mathrm{F}$.

As ferramentas computacionais são muito utilizadas na análise emergética, de modo que, auxiliam na comparação entre os diversos índices emergéticos dos processos e/ou produtos envolvidos. Dentre os softwares, destaca-se o Data Envelopment Analysis Online Software (DEAOS), constituído de diversos modelos de programação linear, que avalia a eficiência relativa entre as chamadas Unidades Tomadoras de Decisão (UTD), por meio da análise envoltória de dados. As diferentes UTD's de um processo são entidades que realizam tarefas similares e se diferenciam pela quantidade de recursos utilizados (entradas) e produzidos (saídas) (Wilhelm et al., 2009).

Este software possui dois modelos matemáticos básicos: o de Charnes, Cooper e Rhodes (CCR), formulado em 1978 e o de Banker, Charnes e Cooper (BCC), formulado em 1984 (Charnes et al., 1978; Banker et al., 1984). Ambos os modelos estabelecem razões entre as grandezas de saída e de entrada por meio de diversos pesos ótimos, que buscam maximizar a eficiência daquela unidade. A principal diferença entre esses dois modelos é que o primeiro é utilizado em sistemas nos quais as saídas são diretamente proporcional às entradas, fato que não ocorre para o segundo modelo citado.

Em vista disso, este trabalho tem por objetivo avaliar a eficiência energética renovável de fontes alternativas de biomassas (casca de arroz, fibra de coco, resíduo de eucalipto e bagaço de cana-de-açúcar) como matérias-primas de processos de geração de energia em uma usina termelétrica independente, que seguirá o ciclo de Rankine, por meio da análise dos indicadores emergéticos e pelo uso da análise envoltória de dados.

\section{MATERIAIS E MÉTODOS}

\subsection{Biomassas selecionadas}

As biomassas selecionadas para este estudo foram: casca de arroz, fibra de coco, eucalipto, bagaço de cana-de-açúcar, e algumas de suas propriedades podem ser observadas 
na Tabela 1. O poder calorífico inferior foi calculado baseado na composição química e no poder calorífico superior (Higuchi e Tannous, 2015; Farias, 2012;), aplicados na equação de Mendeleev (1949). A energia disponível foi obtida pela multiplicação da massa disponível de cada biomassa pelo respectivo valor de poder calorífico inferior. Esse valor energético foi dividido pela área de cultivo de cada biocombustível, de modo a facilitar a análise conjunta com os valores emergéticos, também mensurados em unidades de área.

Tabela 1 - Disponibilidades das biomassas disponível no Brasil e suas características.

\begin{tabular}{ccccc}
\hline Biomassa & $\begin{array}{c}\text { Massa anual } \\
\text { disponível }(\mathrm{kg})\end{array}$ & $\begin{array}{c}\text { Área de } \\
\text { cultivo (ha) }\end{array}$ & PCI (MJ/kg) & $\begin{array}{c}\text { Energia } \\
\text { disponível (J/ha) }\end{array}$ \\
\hline Casca de Arroz & $3,0 \times 10^{9}$ & $2,60 \times 10^{6}$ & 12,28 & $1,42 \times 10^{10}$ \\
Fibra de Coco & $2,2 \times 10^{9}$ & $2,87 \times 10^{5}$ & 14,41 & $1,12 \times 10^{11}$ \\
Eucalipto & $4,5 \times 10^{10}$ & $5,10 \times 10^{6}$ & 16,55 & $1,46 \times 10^{11}$ \\
Bagaço de Cana & $1,3 \times 10^{11}$ & $6,92 \times 10^{6}$ & 16,37 & $3,05 \times 10^{11}$ \\
\hline
\end{tabular}

\subsection{Levantamento de dados da literatura}

Cada biomassa teve todo seu ciclo de produção mapeado considerando todas as contribuições no processo de cultivo ou de recuperação de resíduos. Além disso, procurou-se avaliar as condições climáticas nas quais as biomassas foram cultivadas, visto que, sol, chuva e vento (fontes de recursos naturais renováveis), três fatores determinantes na emergia total de cada produto, característicos da região nas quais as mesmas são cultivadas; recursos naturais não renováveis (como a perda de matéria orgânica do solo); recursos de serviços (como despesas administrativas, mão de obra, tarifas e impostos, assistência técnica) e recursos materiais (como combustíveis, fertilizantes, aço para o maquinário, sementes).

Os dados utilizados no presente trabalho foram baseados em valores encontrados na literatura, de modo que com base nesses valores, foi feita uma análise meticulosa levando em consideração a análise emergética. As fontes de estudo para cada biomassa foram: casca de arroz (Teixeira et al., 2007); fibra de coco (Ortega, 2004); eucalipto (Agostinho, 2009); bagaço de cana-de-açúcar (Agostinho, 2009).

\subsection{Uso dos Indicadores Emergéticos e Eficiência Relativa através da Análise Envoltória de Dados}

O modelo matemático escolhido para este trabalho foi o Charnes, Cooper e Rhodes (CCR) no qual foram estabelecidas duas entradas (2) e duas saídas (2). Para as grandezas de entrada foram utilizadas o indicador emergético Transformidade (Tr) e o inverso da massa disponível (Tabela 1) para cada biomassa (1/M). Para as saídas foram estabelecidos os indicadores, Renovabilidade (\%R) e Razão de Rendimento Emergético (EYR). As definições e equações foram apresentadas na introdução do presente trabalho.

A orientação direcionada para o modelo foi a de minimizar as entradas. Por isso, utilizou-se o inverso da massa disponível, garantindo que as biomassas de maior valor de produção de resíduos, apresentassem também, menor valor para as entradas. A Equação 1 representa a eficiência energética renovável relativa para o sistema de 2 x 2 . 


$$
\max \theta=E E R R=\frac{u_{1} y_{1}+u_{2} y_{2}}{v_{1} x_{1}+v_{2} x_{2}}
$$

sendo max $\theta$ a eficiência máxima (EERR) de cada unidade tomadora de decisão (UTD), u e v são os pesos ótimos para cada UTD em estudo, que devem ser maiores ou iguais a zero, e y e $\mathrm{x}$ as saídas e entradas, respectivamente. A Equação 1 deve seguir algumas restrições para que o modelo possa ser aplicado de maneira correta. A primeira delas é garantir que o denominador seja igual a 1 (Equação 2) e a segunda é assegurar que o valor dessa razão seja menor ou igual a 1 .

$$
v_{1} x_{1}+v_{2} x_{2}=1 \quad \text { e } \quad \frac{u_{1} y_{1}+u_{2} y_{2}}{v_{1} x_{1}+v_{2} x_{2}} \leq 1
$$

Como foi definido pela Equação 2, o denominador deve apresentar valor unitário, a eficiência da biomassa é calculada pela Equação 3:

$$
\max \theta=u_{1} y_{1}+u_{2} y_{2}
$$

Pela condição retratada na Equação 2, o valor do denominador deve ser maior ou igual ao valor encontrado no numerador, conforme Equação 4:

$$
u_{1} y_{1}+u_{2} y_{2} \leq v_{1} x_{1}+v_{2} x_{2}
$$

Um sistema de 14 equações foi estabelecido e as Unidades Tomadoras de Decisão (biomassas) comparadas a fim de verificar entre estas suas eficiências comparativas. A resolução desse sistema de equações foi obtida por meio da utilização do programa Excel, versão 2007, juntamente com a ferramenta Solver, ajustada para assumir apenas modelos lineares e valores não negativos.

\section{Resultados e discussão}

\subsection{Ciclo de produção das biomassas}

A contabilização dos dados de produção para as biomassas em estudo, juntamente com os indicadores emergéticos obtidos podem ser observados na Tabela 2.

Tabela 2 - Dados emergéticos para as biomassas em estudo.

\begin{tabular}{cccccc}
\hline Biomassa & $\begin{array}{c}\text { Emergia Total } \\
(\text { seJ/ha.ano) }\end{array}$ & $\operatorname{Tr}(\mathrm{seJ} / \mathrm{J})$ & $\% \mathrm{R}$ & EYR (-) & EERR (\%) \\
\hline Casca de Arroz & $4,69 \times 10^{16}$ & $3,31 \times 10^{6}$ & 77,58 & 4,46 & 14 \\
Fibra de Coco & $5,36 \times 10^{15}$ & $4,77 \times 10^{4}$ & 19,81 & 1,26 & 90 \\
Eucalipto & $7,26 \times 10^{15}$ & $4,98 \times 10^{4}$ & 15,97 & 1,56 & 70 \\
Bagaço de Cana & $8,73 \times 10^{15}$ & $2,86 \times 10^{4}$ & 13,27 & 1,28 & 100 \\
\hline
\end{tabular}

Pela análise da Tabela 2, observa-se que o arroz foi a biomassa com maior quantidade de energia acumulada (emergia total), devido principalmente ao uso de água de irrigação, o 
que eleva a contribuição energética no processo. Isso impacta diretamente nos índices emergéticos. A transformidade se eleva pelo fato da casca ser a biomassa com a menor quantidade de energia disponível (Tabela 1) associada ao seu baixo pode calorífico (alto teor de cinzas). A renovabilidade foi elevada pelo fato de se considerar a água de irrigação como uma fonte natural renovável, causando um aumento desse indicador em relação as outras biomassas. O potencial emergético (EYR) se elevou pelo mesmo motivo refletindo nas contribuições da economia.

O bagaço e o eucalipto apresentaram valores próximos de emergia total, ambos provenientes de processos de produção consolidados e já estabelecidos no cenário nacional. $\mathrm{O}$ menor valor de transformidade do bagaço pode ser atribuído ao alto valor de energia disponível para a queima, já que essa biomassa é a que apresenta maiores valores de produção disponível. Os altos valores de produção implicam também em uma razão 1/M baixa, o que garante que esta biomassa necessite de menores quantidades de insumos para produzir melhores resultados.

A fibra de coco apresentou valores de renovabilidade mais elevados que o eucalipto e o bagaço. Isso pode ser explicado pelo maior valor de recursos naturais empregados no ciclo de produção desta biomassa. Os indicadores da fibra merecem ser ressaltados, visto que se trata de uma produção significativa e sustentável.

O eucalipto apresentou um valor de rendimento emergético (EYR) superior ao do bagaço e da fibra, isso se deve ao fato de não se tratar de uma cultura mecanizada e nem de um gênero alimentício, e sim, de uma matéria-prima de interesse para a indústria de papel e celulose. O que permite a menor dependência das contribuições econômicas (maquinário, mão de obra, fertilizantes de modo geral) no ciclo de produção.

Em consequência destes fatos, a EERR foi de baixo desempenho para a casca de arroz devido a baixa disponibilidade de massa quando comparada as outras biomassas em estudo e pelo alto valor de energia necessário para sua produção. Esses altos valores de entrada para a casca impossibilitaram um bom desempenho, mesmo que as saídas apresentassem resultados satisfatórios. As outras biomassas mostram-se bastante satisfatórias (70-90\%) e o bagaço de cana-de-açúcar mostrou a melhor biomassa para geração de energia (100\%).

\section{Conclusão}

O desenvolvimento de uma planilha como uma ferramenta matemática mostrou-se válido para a resolução do modelo de Charnes, Cooper e Rhodes (CCR), tornando-se uma alternativa em relação ao uso do software DEAOS (Data Envelopment Analysis Online Software).

A análise dos indicadores e o resultado do modelo CCR permitiu escolher e classificar as biomassas de acordo com a eficiência energética e sustentável das mesmas. O bagaço foi a biomassa mais eficiente dentre as estudadas, seguido pela fibra de coco, resíduo de eucalipto e casca de arroz. Destaca-se entre os potenciais biocombustíveis, a fibra de coco, pela sua alta eficiência energética renovável, superior ao eucalipto, sendo uma biomassa já consolidada no cenário nacional. 


\section{Agradecimentos}

Os autores agradecem ao PIBIC/CNPq pelo apoio financeiro deste trabalho.

\section{Referências Bibliográficas}

AGOSTINHO, F. Estudo da sustentabilidade dos sistemas de produção agropecuários da bacia dos rios Mogi-Guaçú e Pardo através da análise emergética. 204p.Tese de doutorado, Universidade Estadual de Campinas: Campinas. 2012.

BANKER, R. D.; CHARNES, A.; COOPER, W. W. Some models for estimating technical and scale inefficiencies in data envelopment analysis. Manager Science, v. 30, n. 9, p. 2-5, 1984.

BRANDT-WILLIAMS, S. L. Handbook of emergy evaluation: A compendium of data for emergy computation issued in a series of folios. Folio 4. Emergy of Florida Agriculture. Center for Environmental Policy. University of Florida, Gainesville, Flórida, EUA, 2002.

CARMO, V. B. Avaliação da eficiência energética renovável de biomassas alternativas para geração de eletricidade. 163p. Tese de doutorado, Universidade Estadual de Campinas, Campinas, SP, 2013.

CHARNES, A.; COOPER, W.W.; RHODES, E. Measuring the efficiency of decision making units. European Journal of Operational Research, v. 2, n. 6, p.429-444. 1978.

FARIAS, F. O. M. Caracterização de biomassas brasileiras para fins de aproveitamento energético.Tese de Mestrado, Universidade Estadual de Campinas: Campinas. 2012.

HIGUCHI, L.; TANNOUS, K. Avaliação da produtividade de biomassas lignocelulósicas e potencial de utilização para fins energéticos. (Ed.) Katia Tannous, Universidade Estadual de Campinas, Campinas, SP, 2015. ISBN 978-85-918766-0-0.

MENDELEEV, D. Sochineniya (Collection of Works), Anais da Academia de Ciência da URSS. Moscou, URSS, 1949.

ODUM, H. T. Environmental accounting - Emergy and environmental decision making. John Wiley \& Songs, INC., Nova Iorque, EUA, 1996, 384p.

ORTEGA, E. Ciclo Emergético para o coco. Disponível em: <http://www.unicamp.br/ fea/ortega/xml/coco-m-data.xml, 2004>. Acesso em: 26. Jan. 2015.

TEIXEIRA, G. G.; CARVALHO, R. V.; COSTA, A. V. Análise econômica e emergética num sistema integrado de produção de arroz irrigado em transição para o cultivo orgânico. Revista Brasileira Agrociência, v. 13, p. 319-324, 2007.

WILHELM, V. E.; SOUZA, P. C. T. Uma introdução aos modelos DEA de eficiência técnica. Tuiuti: Ciência e Cultura, n. 42, p.121-139, Curitiba, 2009.

ZHANG, G.; LONG, W. A key review on energy analysis and assessment of biomass resources for a sustainable future. Energy Policy, v.38, n.6, p.2948-2955, 2010. 